Special issue of the 2nd International Conference on Computational and Experimental Science and Engineering (ICCESEN 2015)

\title{
Nanomechanical Properties of Different Dental Restorative Materials
}

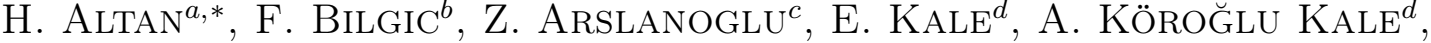
A. $\operatorname{ALtan}^{e}$ AND O. SAHIN $f$

${ }^{a}$ Gaziosmanpaşa University, Faculty of Dentistry, Department of Pediatric Dentistry, Tokat, Turkey

${ }^{b}$ Mustafa Kemal University, Faculty of Dentistry, Department of Orthodontics, Hatay, Turkey

${ }^{c}$ Mustafa Kemal University, Faculty of Dentistry, Department of Paediatric Dentistry, Hatay, Turkey

${ }^{d}$ Mustafa Kemal University, Faculty of Dentistry, Department of Prosthodontics, Hatay, Turkey

${ }^{e}$ Gaziosmanpaşa University, Faculty of Dentistry, Department of Maxillofacial Surgery, Tokat, Turkey

${ }^{f}$ Mustafa Kemal University, Faculty of Art and Science, Micro/Nanomechanic Characterization Laboratory, Hatay, Turkey

The aim of this study is to determine the hardness and roughness of glass ionomer cement, glass carbomer, and compomer by nanoindentation. Three different dental restorative materials: glass ionomer cement, glass carbomer cement, and compomer were used. Disc specimens $(10 \mathrm{~mm} \times 1 \mathrm{~mm})$ were prepared from each material using teflon mold. All specimens were light cured according to the manufacturer's instructions. The specimens were then mounted in polyacrilic resin. After grinding and polishing the specimens were stored in distilled water at $37^{\circ} \mathrm{C}$ for 1 day. The specimens were investigated using nanoindenter. The highest nanohardness was measured for glass ionomer cement and the lowest for glass carbomer. Regarding roughness, glass ionomer cement and compomer showed the highest mean values. Glass ionomer cement and compomer exhibited similar nanomechanical properties. Glass carbomer had superior ability to be polished up.

DOI: 10.12693/APhysPolA.130.394

PACS/topics: 62.20.-x, 62.20.Qp

\section{Introduction}

The response of a material against changes around is called "physical properties". Physical properties are analyzed in three groups: mechanical properties, thermal properties, and electrochemical properties [1]. Measurements can be made by applying testing and standards at the nanoscale with mechanical properties such as macro, micro, and advanced technology [2, 3]. Hardness, roughness, wear resistance, and fracture toughness are involved in those mechanical properties [1-4].

Hardness is called the resistance of a sample against the applied force indicating to this sample [5]. Hardness of restorative materials is important in order not to damage the surrounding tissues in contact in the mouth. Surface roughness (Ra) is a reason for external discoloration and is related to the type of restorative material.

In most conventional mechanical testing methods, measurement of multiple features in a single test is difficult $[5,6]$. In studies on mechanical properties of dental materials using conventional testing methods the obtained penetration appears to be subjective because the direction and size of the applied force is based on the preference of the researcher [2]. Application of nanoindentation method of testing the mechanical properties of materials is an important development in dentistry.

Many restorative materials are produced as a result of the development of technology. Glass ionomer cement

\footnotetext{
* corresponding author; e-mail: halenuronat@gmail.com
}

(GIC) and compomer are the most preferred materials in pediatric dentistry [7]. Glass ionomer cement has a wide application area because of its advantages [8]. However, its use on permanent teeth at locations facing occlusal forces is restricted [8]. A restorative material called EQUIA $^{\mathrm{TM}}, \mathrm{GC}^{\circledR}$ managed to reduce the negative properties of GICs in recent years [9].

Glass carbomer cement is manufactured to eliminate the negative properties of GIC - the most preferred restorative material in pediatric dentistry [10-12]. Nanosized particles and fluorapatite are among the ingredients of this new material [12].

Compliance of a dental restorative material with dental hard tissue in regard of biological, chemical, mechanical and physical properties is an important issue for the success of treatment and clinical performance of the materials. Yet, the search for highly polishable restorative material with similar to dental hard tissue hardness properties continues in modern dentistry.

The aim of this study was to investigate the hardness and roughness of three different restorative materials on a nanoscale, to gain information and to assist on the understanding of the degradation of these materials on macroscale.

\section{Materials and methods}

The presented study examined 3 different dental filling materials. Specimens tested were prepared for nanohardness testing using high viscosity GIC (EQUIA, GC), compomer (Dyract eXtra, Dentsply) and glass carbomer (Glass Carbomer, GCP). 
Twenty $10 \mathrm{~mm}$ thick parallel poly-methyl methacrylate (PMMA) cylinders with $50 \mathrm{~mm}$ diameter were fabricated. In the center of one of the flat surfaces of each cylinder block a $2 \mathrm{~mm}$ deep and $10 \mathrm{~mm}$ wide circular cavity was prepared and cyanoacrylate (CA) adhesive was applied on all of its margins. PMMA blocks were randomly divided into 3 groups with 3 cylinders each and the prepared cavities were filled with one of the tested dental filling materials, according to their group.

Group 1. High viscosity GIC (GC, Japan) was used to fill the cavity; a capsule mixer (Linea Tac 400M) was used for $10 \mathrm{~s}$ for mixing prior to the application of the material with a Fuji Applicator. The specimen was subjected to a $1400 \mathrm{~mW}$ light heating procedure (Ultradent, USA) for 5 s during the chemical setting process.

Group 2. Compomer (Dentsply, USA) was used to fill the cavity; a compules tip gun was used. The specimens were subjected to a $1400 \mathrm{~mW}$ light heating procedure (Ultradent, USA) for $20 \mathrm{~s}$ during the chemical setting process.

Group 3. Glass carbomer (GCP, Holland) was used to fill the cavities; a capsule mixer (Linea Tac 400M) was used for $10 \mathrm{~s}$ for mixing prior to the application of the material with a GCP carboCAP Applicator. The specimens were subjected to a $1400 \mathrm{~mW}$ light heating procedure (GCP Carboled Lamp, Holland) for $60 \mathrm{~s}$ of light curing.

\subsection{Nanohardness and surface roughness tests}

24 hours after the application of each material, irregularities on the surfaces due to manual application procedures were smoothed mechanically by grinding with 1200, 2400 and 4000 grit sandpaper for 1 min durations, consecutively. Each specimen was subjected to the Vickers test 3 times at $24 \mathrm{~h}$ after material application. Nanomechanical tests of the materials were performed with Hysitron TI 950 TriboIndenter nanomechanical test instrument. This machine load resolution is less than $1 \mathrm{nN}$ and displacement resolution $0.04 \mathrm{~nm}$. The Berkovich diamond indenter tip was used for measuring the mechanical properties (nanohardness) of specimens. The tip was calibrated with a fused quartz reference sample. In order to record the morphological images of the indents, the nanoindenter was also operated in scanning probe mode (SPM). Surface roughness of the samples was measured using SPM. In this study, maximum load was determined as $6000 \mu \mathrm{N}$ under a loading/unloading rate of $1200 \mu \mathrm{N} / \mathrm{s}$, and the load was held at each maximum value for $2 \mathrm{~s}$. For a particular load at least 6 indentation tests were conducted on the sample surface to increase the reliability of the experimental results. The Oliver-Pharr [13] method was used to analyze the nanoindentation load-displacement curves. In this model contact area and nanohardness were defined as $H_{\text {nano }}=\frac{P_{\max }}{A}, A_{c}=24.5 h_{c}^{2}$.

\section{Results}

Applied indentation test load-displacement curves during nanoindentation tests for the restorative materials are shown in Fig. 1 and an image is shown in Fig. 2.

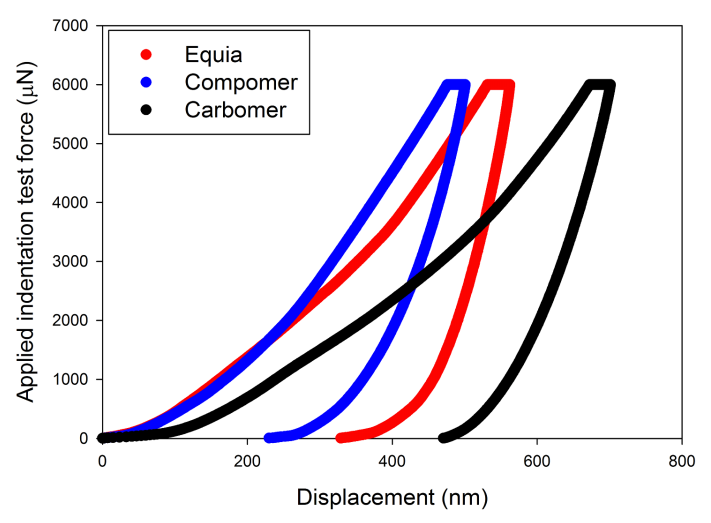

Fig. 1. Applied indentation test force versus displacement of examined materials.

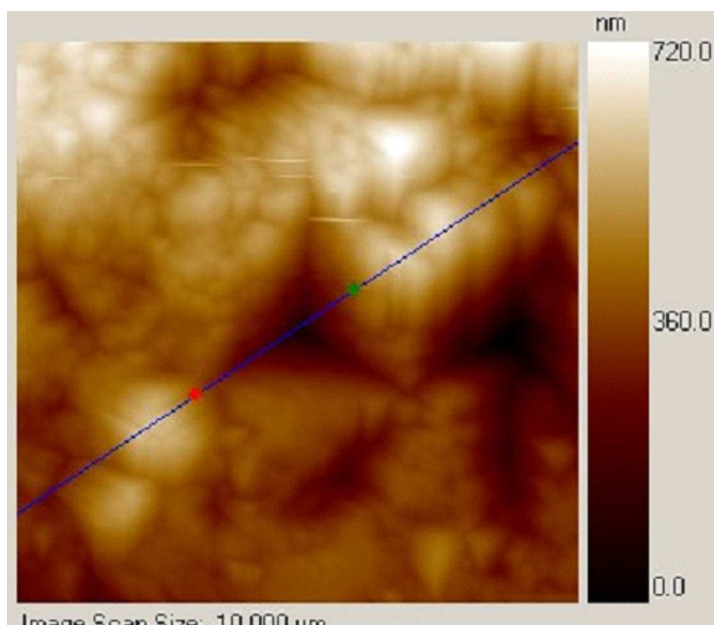

Fig. 2. Image showing the indent impression on glass carbomer cement.

Figure 1 exhibits 3 different load-unload indentation cycles for the tested materials. The curves demonstrate a smooth shape and no pop-in can be detected. The nanohardness values were calculated according to the Oliver-Pharr [13] model using the applied indentation test load-displacement curves. Hardness and average roughness values are given in Table I.

TABLE I

Mean values of hardness $[\mathrm{GPa}]$ and average roughness $(\mathrm{Ra})[\mathrm{nm}]$ of the specimens.

\begin{tabular}{c|c|c}
\hline \hline Materials & Hardness & $\mathrm{Ra}(\mathrm{nm})$ \\
\hline glass ionomer cement (EQUIA) & 1.863 & 205.245 \\
compomer (Dyract eXtra) & 0.780 & 187.512 \\
glass carbomer cement (GCP) & 0.603 & 90.489
\end{tabular}

The hardness values of compomer and carbomer groups were similar. The hardness values of GIC were the highest among the groups. The roughness values of GIC cement and compomer were similar and higher than 
glass carbomer cement. The smoothest surface was observed in the glass carbomer cement group.

\section{Discussion}

A high compliance of biological, chemical, mechanical, and physical properties of the dental restorative materials with dental hard tissues is of great importance in terms of success of treatment and its clinical performance to the dental practice [14]. The fact that the restorations placed in occlusal areas are subjected to masticatory forces is related to the hardness of a material and that property needs to be similar to that of the enamel and dentin tissue for the good of the treated teeth and their healthy antagonists. It was reported that nanohardness of dental tissues was in different value range as enamel was 3.6$5.7 \mathrm{GPa}$ and dentine was $0.5-1.1 \mathrm{GPa}$, whereas composite is $0.5-2.2 \mathrm{GPa}$ and GIC is $0.31-1.9 \mathrm{GPa}$, for example [1520]. In our study, as a result of the comparison of dental materials, it was observed that compomer $(0.780 \mathrm{GPa})$ and glass carbomer cement $(0.603 \mathrm{GPa})$ had different mechanical properties compared to GIC $(1.863 \mathrm{GPa})$. GIC had the most approximate values to that of permanent tooth enamel's mechanical properties.

The surface roughness of restorative materials is a property that should be noticed in terms of retention and proliferation of bacteria in mouth environment. Bollen et al. [21] reported that the rough surface of the tooth should be less than $0.20 \mu \mathrm{m}$. In our study, glass carbomer and compomer were below this value, and GIC was exactly at the limit. The surface roughness of compomer was higher than glass carbomer therefore closer to GIC in terms of roughness. In a study carried out by Arslanoglu et al. [22], it was reported that the glass carbomer at micro level had less surface roughness than GIC. The nanovalues in terms of roughness obtained from this study support those results. The high polishing ability of glass carbomer may be attributed to the high rate nanoparticles contained in the glass material. As highly polishable dental materials retain less residue of foreign material contamination that may often be a cause of biological pigmentation on tooth colored surfaces due to pigment penetration on rough areas, it may be speculated the color properties of glass carbomer may last for longer than the other tested restoratives in this study without early discoloration.

\section{Conclusion}

The GIC with high viscosity (EQUIA) can be used as an alternative to compomer especially in pediatric dentistry regarding its high standard biomechanical properties. The glass carbomer is not different from nanomechanical structure point compared to compomer, and both materials have similar properties to dentine rather than enamel dental hard tissue.

\section{Acknowledgments}

This study was supported by the Turkish State Planning Organization (DPT) with project No. 2010K121220 and it also supported by the Scientific Research Commission of Mustafa Kemal University (BAP) (project No. 12880).

\section{References}

[1] R. Asaro, V. Lubarda, Mechanics of Solids and Materials, Cambridge University Press, Cambridge 2006.

[2] R. Gallagher, M. Balooch, G. Balooch, R. Wilson, S. Marshall, G. Marshall, J. Dental Biomech. 1, 256903 (2010).

[3] D.M. Ebenstein, in: Handbook of Nanoindentation with Biological Applications, Ed. M.L. Oyen, Pan Stanford Publ., Singapore 2010, p. 279.

[4] R. Silva, A. Zuanon, R. Esberard, M. Candido, J. Machado, J. Mater. Sci. Mater. Med. 18, 139 (2007).

[5] C. Bréchignac, P. Houdy, M. Lahmani, Nanomaterials and Nanochemistry, Springer Sci. and Business Media, France 2008.

[6] O. Sahin, O. Uzun, M. Sopicka-Lizer, H. Gocmez, U. Kölemen, J. Europ. Ceram. Soc. 28, 1235 (2008).

[7] P. Dionysopoulos, N. Kotsanos, Y. Papadogianis, J. Oral Rehabilit. 23, 511 (1996).

[8] U. Lohbauer, Materials 3, 76 (2009).

[9] J.D. Scholtanus, M.-C.D. Huysmans, J. Dentistry 35 , 156 (2007).

[10] F. Ghaderi, A. Mardani, J. Dental Res. Dental Clin. Dental Prosp. 9, 92 (2015).

[11] K. Gorseta, D. Glavina, A. Borzabadi-Farahani, R.N. Van Duinen, I. Skrinjaric, R.G. Hill, E. Linch, Europ. J. Prosthodont. Restorat. Dentistry 22, 67 (2014).

[12] U. Menne-Happ, N. Ilie, J. Dent. 41, 223 (2013).

[13] W.C. Oliver, G.M. Pharr, J. Mater. Res. 7, 1564 (1992).

[14] L.H. He, M.V. Swain, J. Mech. Behav. Biomed. Mater. 1, 18 (2008).

[15] S. Poolthong, Ph.D. Thesis, University of Sydney, Sydney, Australia 1998.

[16] H. Fong, M. Sarikaya, S.N. White, M.L. Snead, Mater. Sci. Eng. C 7, 119 (1999).

[17] M. Da, R.J. Young, A.B. Mann, D.C. Watts, Arch. Orofac. Sci. 2, 26 (2007).

[18] L. Zheng, J. Zheng, L. Weng, L. Qian, Z. Zhou, Wear 271, 2297 (2011).

[19] F. Lippert, D.M. Parker, K.D. Jandt, J. Coll. Interface Sci. 280, 442 (2004).

[20] J. Zhou, L.L. Hsiung, J. Biomed. Mater. Res. Part A $\mathbf{8 1 A}$, 66 (2007).

[21] C.M. Bollenl, P. Lambrechts, M. Quirynen, Dent. Mater. 13, 258 (1997).

[22] Z. Arslanoglu, H. Altan, O. Sahin, M. Tekin, M. Adigüzel, Acta Phys. Pol. A 128, B-310 (2015). 